\title{
Search of Noise Source of Spiral Vacuum Pump
}

\author{
Kunihiko Ishihara, Tomoya Hamada, Toshinobu Iwamoto, Akari Goto, Masanobu Tsurumoto
}

\begin{abstract}
A Spiral vacuum pump is widely used in a low noise type suction truck. When the pump is operated, a large gear noise generates and some countermeasures are required. Then it is necessary to search the noise source position for countermeasure. Several studies are conducted to search the noise source position. As a result, it was clarified that the noise source position was not from the gear casing which is immediately think up but from an elbow near the spiral vacuum pump. In order to clarify the result, the noise source search was performed by using the current searching technique (Sound Brush made by LMS) which is 3D intensity meter and we confirmed it.
\end{abstract}

Index Terms - Noise source search, Spiral vacuum pump, Acoustic intensity, Suction truck

\section{INTRODUCTION}

The low noise suction truck which is the product of $\mathrm{A}$ company uses a spiral vacuum pump to reduce the noise. The reason is that the spiral pump is generally said to be low noise. The high level sound was generated when the spiral pump was operated. In general, the main noise source is a gear noise generated from the gear which transmits the power from driving shaft to the following shaft [4]-[8]. Then the gear noise is thought to be transmitted from the gear casing. We therefore thought that the transmitted noise can be reduced by changing the material of the casing from the aluminum to the cast steel. But it was proved that the gear noise could not be reduced by measuring the noise after changing the material. This fact means the noise source is not the transmitting noise from the gear casing and it was needed to know where the true noise source was. In this paper, it will be described that some examinations are conducted in order to clarify the true noise source.

\section{EXPERIMENT}

Figure1 shows the experimental equipment. The noise was

Kunihiko Ishihara, Department of Health and Welfare, Tokushima Bunri University, Shido, Sanuki-city, Kagawa, Japan, +81878945111.

Tomoya Hamada, Engineering Division, Kanematsu Engineering CO., LTD., 898-20 Myoken, Nankoku, Kochi, Japan, Phone+81352973767.

Toshinobu Iwamoto, Engineering Division, Kanematsu Engineering CO.,LTD., 898-20 Myoken, Nankoku, Kochi, Japan, Phone+81352973767.

Akari Goto, Department of Health and Welfare, Tokushima Bunri University, Shido, Sanuki-city, Kagawa, Japan, +81878945111.

Masanobu Tsurumoto, Department of Health and Welfare, Tokushima Bunri University, Shido, Sanuki-city, Kagawa, Japan, +81878945111. measured by use of the noise meter (NL-42, made by Rion company ) and the noise detection was performed by using the Sound Brush made by LMS.

The measurement was carried out as follows.

1. The power was taken out from a motor and the pump is rotated. The rotating speed is set at $2400 \mathrm{rpm}$.

2 . The valve attached the suction piping is gradually closed and the vacuum pressure is measured by the mercury manometer (Set pressure : $-700[\mathrm{mmHg}] \fallingdotseq-93[\mathrm{kPa}]$ ) . At this time the cooling water is taken out from the tap water and the flow rate is set constant.

3. The sound pressure level was measured and investigated by the noise meter. The noise with the fundamental frequency of $1960 \mathrm{~Hz}$ made by the gear was generated.

Where the fundamental frequency of the gear is calculated by $\mathrm{f}=\frac{\mathrm{n}}{60} \times N \quad(\mathrm{n}$ : Rotating speed $[\mathrm{rpm}]=2400, \mathrm{~N}$ : Number of gear teeth $=49$ )

4. It was judged from the sense of hearing actually and the measurement result that the noise was transmitted not from the gear casing but from the elbow of the suction piping.

5. In the state that the elbow part was covered by the blanket, the noise was measured at the point $1 \mathrm{~m}$ apart from the pump surface and frequency analyzed.

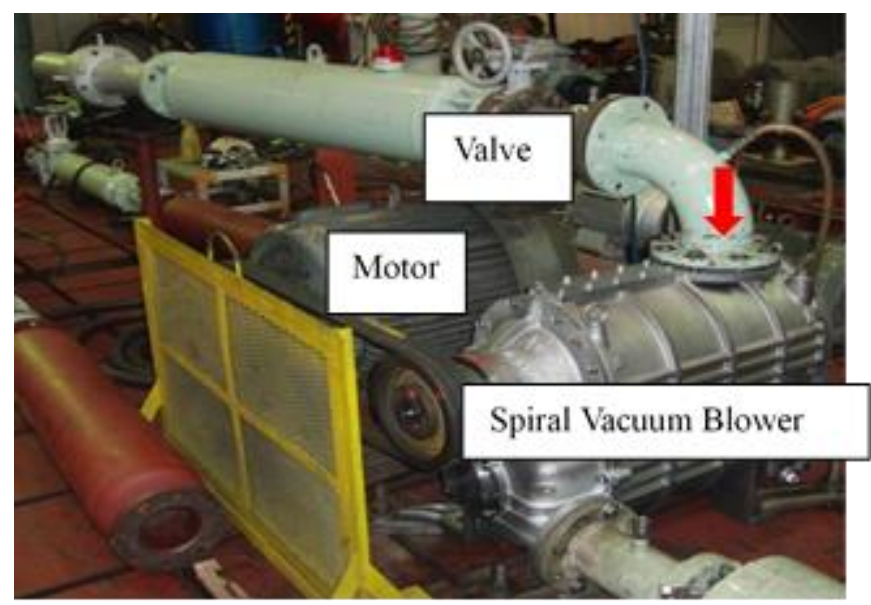

Fig.1 Experimental equipment

Figure2 shows the spectrum result of the noise level measured at the discharge piping side under the condition of with /without blanket. Figute 3 shows the enlarged view of Figure2. From this figure, it was clarified that the blanket suppressed the noise $13.5 \mathrm{~dB}$ of $1960 \mathrm{~Hz}$ component which is the gear noise.

That is to say, it was confirmed that the noise of $1960 \mathrm{~Hz}$ component can be reduced by preventing the transmitting noise from the elbow. However, the noises of $1920 \mathrm{~Hz}$, $2000 \mathrm{~Hz}$, and $2040 \mathrm{~Hz}$ could not be reduced. These frequencies 


\section{Search of Noise Source of Spiral Vacuum Pump}

are presumed to be the noise caused by the shaft vibration. But this is not mentioned here.

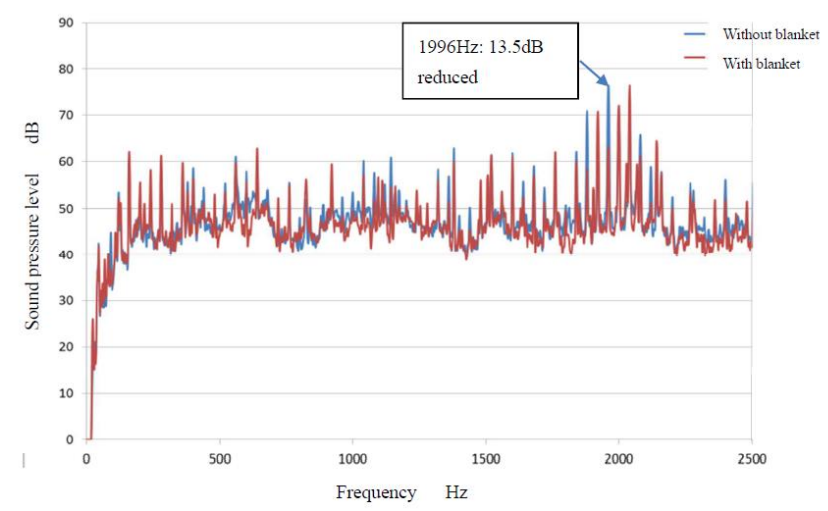

Fig. 2 FFT result of sound from discharge side

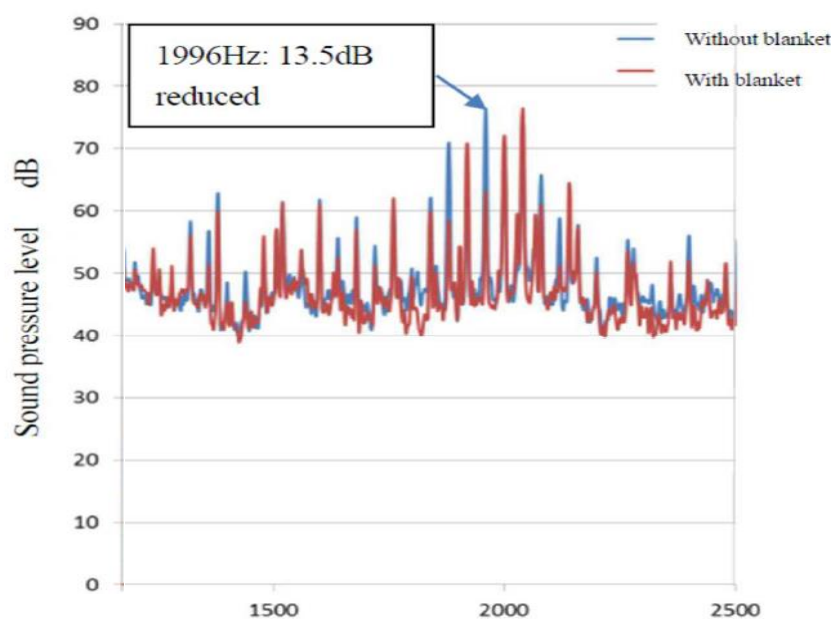

Fig.3 Enlarged view of Fig.2

\section{NOISE SOURCE EXPLORATION}

The Sound Brush made by LMS company used here to explore the noise source. It can visualize the noise real timely by combining the $3 \mathrm{D}$ acoustic intensity and the noise exploration. We can obtain the detail results such as the acoustic intensity, acoustic propagation and acoustic power value there.

\section{A. Measurement principle of acoustic intensity}

The acoustic intensity is the acoustic energy passing through the unit area per unit time. The unit is $\mathrm{J} / \mathrm{t} / \mathrm{m}^{2}=\mathrm{W} / \mathrm{m}^{2}$. Describing the sound pressure by $p(\mathrm{t})$ and the particle velocity by $u(\mathrm{t})$ at the measuring point, the acoustic intensity is defined by time average of product of the both physical quantities.

As the particle velocity is the vector quantity and the sound pressure is the scalar quantity the acoustic intensity becomes the vector quantity. Here the sound pressure and the particle velocity are given as follows [3],[4].

$$
\begin{aligned}
& p_{m}(\mathrm{t})=\frac{p_{1}(t)+p_{2}(t)}{2} \\
& u_{m}(\mathrm{t})=-\frac{1}{\rho \Delta r} \int_{-\infty}^{t}\left\{p_{2}(\tau)-p_{1}(\tau)\right\} d \tau
\end{aligned}
$$

Therefore, the acoustic intensity I becomes the next equation.

$$
\mathbf{I}=\lim _{T \rightarrow \infty} \frac{1}{T} \int_{-T / 2}^{T / 2} p(t) \boldsymbol{u}(t) d t
$$

Substituting Eq. (1) and (2) into Eq. (3)

$$
\mathbf{I}=\lim _{T \rightarrow \infty} \frac{1}{T} \int_{-T / 2}^{T / 2} \frac{p_{1}(t)+p_{2}(t)}{2 \rho \Delta r} \int_{-\infty}^{t}\left\{p_{2}(\tau)-p_{1}(\tau)\right\} d \tau d t
$$

can be obtained. Where $\mathrm{T}$ is a time.

In many intensity measuring instrument, almost all the acoustic intensity can be obtained in the frequency domain.

Fourier transforming Eq. (4), the acoustic intensity can be obtained by the imaginary part of the cross spectrum calculated by use of two sound pressures $p_{1}(\mathrm{t}) 、 p_{2}(\mathrm{t})$ measured by two microphones. Where $\omega$ is the angular frequency.

$$
\begin{aligned}
& I=\int_{-\infty}^{\infty} I(\omega) d \omega \\
& I(\omega)=-\frac{I_{m}[\mathrm{G} 21(\omega)]}{\rho \omega \Delta r}
\end{aligned}
$$

(See APPENDIX A)

The acoustic intensity of frequency range $B$ which is prescribed by lower and upper limit given $\omega_{1} 、 \omega_{2}$ can be given the next equation.

$$
\mathrm{I}(\mathrm{B})=\int_{\omega_{1}}^{\omega_{2}} I(\omega) d \omega
$$

In $3 \mathrm{D}$ acoustic intensity measurement, the acoustic intensity of $\mathrm{x}, \mathrm{y}, \mathrm{z}$ directions can be obtained by deploying four microphones ( $)$ as shown in figure 3 .

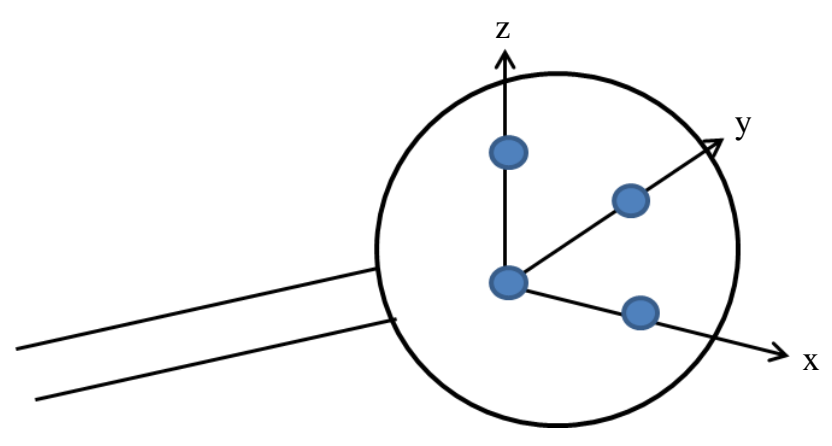

Fig.3 Head of 3D acoustic intensity measurement

\section{B. Measurement result due to acoustic intensity}

The result of the noise detection conducted from discharge side is shown in figure 4.

It can be seen from the figure 4 by focusing the vector of the side of gear casing that the noise distribution is not outer from the surface of gear casing but parallel to the gear casing uniformly. 
It is presumed that this noise is not from the pump but from the motor located side of the pump.

And the position of the highest level noise is the upper part of the flange of suction side this position is near the elbow not shown in the figure.

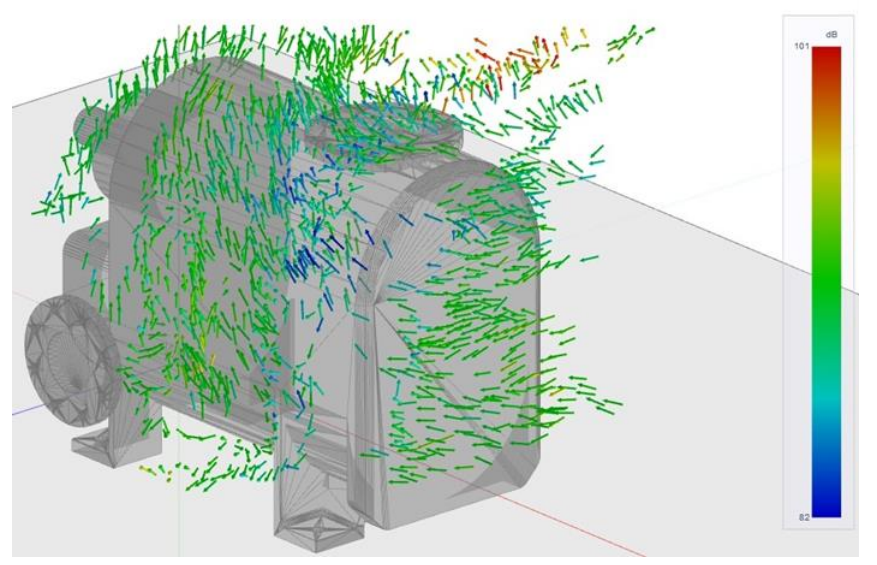

Fig.4 Vector distribution of acoustic intensity due to Sound Brush

\section{CONCLUSIONS}

The noise detection was performed to reduce the environmental noise of the gear casing. As a result, the following findings can be obtained,

(1) The transmitting noise from the gear casing can't be seen in this experiment. Therefore, the change of material from aluminum to cast steel has not merit.

(2) The noise reduction effect can be seen to raise the thick of piping and to use the absorbing material. Because the transmitting gear noise from the suction piping is large.

(3) The acoustic intensity distribution around the gear casing was measured by use of the Sound Brush made by LMS company which is the latest noise detection instrument. As a result, it was clarified that the gear noise was generated not from the gear casing but from the elbow.

(4) The gear noise transmitted from the elbow can be reduced by the above countermeasure. But the causes of other noises could not be specified. The peak noise of other is thought to be the noise generated from the shaft vibration because of the peak concerned integer multiple of the fundamental frequency $40 \mathrm{~Hz}$ of the shaft.

\section{REFERENCES}

[1] A. Horikawa, Analysis of random fluctuation, Kyoritsu Syuppan Co. Ltd, (1970), p.150-174 (in Japanese)

[2] Wylie, C. R., Advanced Engineering Mathematics, Second Edition, (1960), p.475 (in Japanese).

[3] K. Shiraki, edit., Noise prevention design and simulation, Oyo Gijutu Shuppan (1987), p.158 (in Japanese).

[4] H. Yano, Y. Hidaka and H. Tachibana, Visualization of Sound Fields by the Sound Intensity Technique, Noise Control, Vol.15, No.4, 1991, pp.8-12(in Japanese)

[5] Y. Goto, I. Tarutani, H. Tokoro, T. Shimizu and Y. Ueda, Analysis of Structural Vibration for Reducing of Transmission Gear, Noise, International Journal of Automotive EngineeringVol.32, No,3. 2001, pp.81-87(in Japanese).

[6] H. Houjou, Recent Topics of Kow Noise Technology of a Gearing System, Journal of the Japan Society of Precision Engineering, Vol.69, No.3, (2003), pp.349-352(in Japanese).

[7] Y. Goto, Gear Noise Reduction of a Transmission, TOYOTA Central institute D\&D Review, Vol.36, No.1 (2001), p.57(in Japanese)
[8] T. Miyakawa, T. Enomoto, H. Komiya, T. Hatsuta and T. Tanimoto, Vibration Mechanism of the Motor for EV by Analysis ans an Example of the Vibration Reduction Countermeasures, International Journal of Automotive EngineeringVol.45, No,1. 2014, pp.109-113(in Japanese).

[9] E. Kojima, Prediction of Vibration \& Noise of Hydraulic Fluid Power Components and Systems, Noise Control, Vol.25,No.5 (2001), pp.276-282(in Japanese)

\section{APPENDIX A}

Deriving of Eq,(6)

The acoustic intensity is defined as follows [3].

$$
\mathbf{I}=\lim _{T \rightarrow \infty} \frac{1}{T} \int_{-T / 2}^{T / 2} \frac{p_{1}(t)+p_{2}(t)}{2 \rho \Delta r}\left[\int_{-\infty}^{t}\left\{p_{2}(\tau)-p_{1}(\tau)\right\} d \tau\right] d t
$$

The blanket [ ] becomes as follows.

$\int_{-\infty}^{t}\left\{p_{2}(\tau)-p_{1}(\tau)\right\} d \tau=P_{2}(t)-P_{1}(t)-a+b$

Where a and $\mathrm{b}$ are $P_{2}(-\infty)$ and $P_{1}(-\infty)$, respectively.

Substituting Eq.(A-2) to Eq.(A-1) we obtained the next equation.

$$
\mathbf{I}=\lim _{T \rightarrow \infty} \frac{1}{T} \int_{-T / 2}^{T / 2} \frac{p_{1}(t)+p_{2}(t)}{2 \rho \Delta r}\left\{P_{2}(t)-P_{1}(t)-a+b\right\} d t
$$

The autocorrelation function and the cross- correlation function are given as follows [1]-[2].

$$
R(\tau)=\int_{-\infty}^{\infty} P_{1}(t) \cdot P_{1}(t+\tau) d t
$$

$R_{12}(\tau)=\int_{-\infty}^{\infty} P_{1}(t) \cdot P_{2}(t+\tau) d t$

And the relationship of transform pair exists between the correlation function and the spectrum.

$$
\begin{aligned}
& G(\omega)=\int_{-\infty}^{\infty} R(\tau)^{-j \omega \tau} d \tau \\
& R(\tau)=\int_{-\infty}^{\infty} G(\omega)^{j \omega \tau} d \omega \\
& G_{12}(\omega)=\int_{-\infty}^{\infty} R_{12}(\tau)^{-j \omega \tau} d \tau \\
& R_{12}(\tau)=\int_{-\infty}^{\infty} G_{12}(\omega)^{j \omega \tau} d \omega
\end{aligned}
$$

Rewriting Eq.(A-3) we obtained the next equation.

$$
\mathbf{I}=\frac{1}{2 \rho \Delta r} \lim _{T \rightarrow \infty} \frac{1}{T} \int_{-T / 2}^{T / 2}\left\{p_{1}(t)+p_{2}(t)\right\}\left\{P_{2}(t)-P_{1}(t)-a+b\right\} d t
$$

Expanding the inner part of integral

$$
\begin{aligned}
& p_{1}(t) P_{2}(t)+p_{2}(t) P_{2}(t)-p_{1}(t) P_{1}(t) \\
& \quad-p_{2}(t) P_{1}(t)+(b-a)\left\{p_{1}(t)+p_{2}(t)\right\}
\end{aligned}
$$

The integral of each term can be described as follows.

$\lim _{T \rightarrow \infty} \frac{1}{T} \int_{-\frac{T}{2}}^{\frac{T}{2}} p_{1}(t) P_{2}(t) d t=\int_{-\infty}^{\infty} p_{1}(t) P_{2}(t) d t=R_{12}(0)$

Then Eq.(A-8) can be expressed as follows. 


$$
\begin{aligned}
& \frac{1}{2 \rho \Delta r}\left\{R_{12}(0)+R_{2}(0)-R_{1}(0)-R_{21}(0)\right\} \\
& \frac{1}{2 \rho \Delta r}\left\{\int_{-\infty}^{\infty} G_{12}(\omega) d \omega+\int_{-\infty}^{\infty} G_{2}(\omega) d \omega\right. \\
& \left.\quad-\int_{-\infty}^{\infty} G_{1}(\omega) d \omega-\int_{-\infty}^{\infty} G_{21}(\omega) d \omega\right\}
\end{aligned}
$$

Where the autocorrelation becomes the same value even if with time retard. That is to say,

$$
\int_{-\infty}^{\infty} G_{2}(\omega) d \omega=\int_{-\infty}^{\infty} G_{1}(\omega) d \omega
$$

Taking into account the nature of cross-spectrum as shown below,

$$
\begin{gathered}
G_{12}(-\omega)=G_{21}(\omega) \\
G_{12}(-\omega)=G_{12}^{*}(\omega) \\
G_{12}^{*}(\omega)=G_{21}(\omega)
\end{gathered}
$$

Eq.(A-12) can be obtained as follows.

$$
I=\frac{1}{2 \rho \triangle r}\left\{\int_{-\infty}^{\infty} G_{21}^{*}(\omega) d \omega-\int_{-\infty}^{\infty} G_{21}(\omega) d \omega\right\}
$$

We can replace the integral $1 / j \omega$

$\frac{1}{2 \rho j \omega \Delta r}\left\{\operatorname{Re}\left(G_{21}\right)-j \operatorname{Im}\left(G_{21}\right)-\operatorname{Re}\left(G_{21}\right)-j \operatorname{Im}\left(G_{21}\right)\right\}$

$=\frac{-1}{2 \rho j \omega \Delta r} 2 j \operatorname{Im}\left(G_{21}\right)=\frac{-1}{\rho \omega \Delta r} \operatorname{Im}\left(G_{21}\right)$

Therefore

$I=\int_{-\infty}^{\infty} \frac{-1}{\rho \omega \Delta r} \operatorname{Im}\left(G_{21}\right) d \omega$

\section{APPENDIX B}

Deriving of Eq.(A-14)

From

$$
\begin{aligned}
& G_{12}(\omega)=\int_{-\infty}^{\infty} R_{12}(\tau)^{-j \omega \tau} d \tau \\
& G_{12}(-\omega)=\int_{-\infty}^{\infty} R_{12}(\tau)^{j \omega \tau} d \tau=\int_{-\infty}^{\infty} \int_{-\infty}^{\infty} p_{1}(t) p_{2}(t+\tau) d t^{j \omega \tau} d \tau \\
& =\int_{-\infty}^{\infty} \int_{-\infty}^{\infty} p_{1}\left(t^{\prime}-\tau\right) p_{2}\left(t^{\prime}\right) d t^{\prime} e^{j \omega \tau} d \tau \\
& =\int_{-\infty}^{\infty} \int_{-\infty}^{\infty} p_{1}\left(t^{\prime}+\tau\right) p_{2}\left(t^{\prime}\right) d t^{\prime} e^{-j \omega \tau} d \tau \\
& =\int_{-\infty}^{\infty} R_{21}(\tau) e^{-j \omega \tau} d \tau=G_{21}(\omega) \\
& G_{12}^{*}(\omega)=\int_{-\infty}^{\infty} R_{12}(\tau)^{j \omega \tau} d \tau \\
& =\int_{-\infty}^{\infty} \int_{-\infty}^{\infty} p_{1}(t) p_{2}(t+\tau) d t e^{j \omega \tau} d \tau \\
& =\int_{-\infty}^{\infty} \int_{-\infty}^{\infty} p_{1}\left(t^{\prime}-\tau\right) p_{2}\left(t^{\prime}\right) d t^{\prime} e^{j \omega \tau} d \tau \\
& =\int_{-\infty}^{\infty} \int_{-\infty}^{\infty} p_{1}\left(t^{\prime}+\tau\right) p_{2}\left(t^{\prime}\right) d t^{\prime} e^{-j \omega \tau} d \tau
\end{aligned}
$$

$$
\begin{aligned}
& =\int_{-\infty}^{\infty} \int_{-\infty}^{\infty} p_{1}\left(t^{\prime}+\tau\right) p_{2}\left(t^{\prime}\right) d t^{\prime} e^{-j \omega \tau} d \tau \\
& =\int_{-\infty}^{\infty} R_{21}(\tau)^{-j \omega \tau} d \tau=G_{21}(\omega)
\end{aligned}
$$

Kunihiko Ishihara was born in 1947 in Kurashiki City, Okayama Prefecture Japan. He received the B.S. degree from Kobe University in 1969. He got a master's degree in Kobe University in 1971 and earned the Ph.D. degree in Engineering from The Osaka University in 1986.

He worked in Kawasaki Heavy Industry Co. Ltd. as an Mechanical Engineer for 33 years. After that he became a Professor of The University of Tokushima in 2004. He had been studying the vibration and noise control, above all he studied the flow induced vibration and noise problems. He has authored or co-authored over 100 technical journal and over 50 conference papers. He is a fellow of JSME (Japan Society of Mechanical Engineers) now. He is a Professor of Tokushima Bunri University. He teaches a mechanical field subjects for students.

Tomoya Hamada was born in 1991 in Nankoku City, Kochi Prefecture Japan. He received the B.S. degree from Kochi National College of Technology in 2014. He has been working in Kanematsu Engineering Co. Ltd.. He is an engineer in the Technical Division. He has been studying the vibration and the noise control.

Toshinobu Iwamoto was born in 1965 in Nakatosa Town, Koch Prefecture Japan. He received the semi B.S. degree from Kochi National College of Technology in 1986. He has been working in Kanematsu Engineering Co. Ltd. for many years. He is a chief engineer in the Technical Division. He has been studying the vibration and the noise control.

Akari Goto was born in 1984 in Tonosho, Kagawa Prefecture Japan. She received a bachelor's degree (clinical engineering) from Hiroshima International University in 2007. She got a master's degree in 2009 and earned the Ph.D. degree in Medical Engineering from The Hiroshima International University in 2012.

She became a lecturer at Tokushima Bunri University in 2009. And she has been a teacher since 2011 .

She conducts research on blood coagulation, medical materials, and medical device development.

Masanobu Tsurumoto was born in 1984 in Tokushima City, Tokushima Prefecture Japan. He received a bachelor's degree (BLA) from Otemae University in 2015. He got a master's degree (M.A.) from The Open University of Japan Foundation in 2019.He became a lecturer at Tokushima Bunri University in 2019. 